\title{
Applicability of Ground Granulated Blast-Furnace Slag for Precast Concrete Beams Subjected to Bending Moment
}

\author{
Sang-Woo Kim ${ }^{1}$, Chan-Yu Jeong ${ }^{2}$, Jin-Seop Lee ${ }^{3}$ and Kil-Hee Kim** \\ ${ }^{1}$ Research Assistant Professor, Department of Architectural Engineering, Kongju National University, Korea \\ ${ }^{2}$ Doctoral Candidate, Department of Architectural Engineering, Kongju National University, Korea \\ ${ }^{3}$ Managing Director, Sampyo Construction \& Engineering Co., Ltd., Korea \\ ${ }^{4}$ Associate Professor, Department of Architectural Engineering, Kongju National University, Korea
}

\begin{abstract}
This study evaluates the flexural performance of precast concrete beams using ground granulated blastfurnace slag. A total of four specimens with various replacement ratios of ground granulated blast-furnace slag are cast and tested in flexure. The specimens under four-point loading had a shear span-to-depth ratio of 4 and a rectangular section with a width of $200 \mathrm{~mm}$ and an effective depth of $300 \mathrm{~mm}$. It can be shown from experimental results that the specimens with ground granulated blast-furnace slag had a similar flexural performance to the specimen with natural aggregates, regardless of the replacement ratios of ground granulated blast-furnace slag.
\end{abstract}

Keywords: ground granulated blast-furnace slag; precast concrete beams; flexure; ductility

\section{Introduction}

Steel slag is divided into blast-furnace slag and steelmaking slag based on its manufacturing process. Blastfurnace slag is generated from the high-temperature melting of raw materials, such as iron ore, coke, and limestone, in a blast furnace for making pig iron (Manso et al. 2004). Steel-making slag is divided into converter slag and electric-arc-furnace slag, which are industrial by-products generated from a converter or an electric-arc furnace with iron ore or scrap metal, respectively, being the main raw materials. The chemical composition of slag as an industrial byproduct is similar to that of construction materials. The recycling of slag has a great advantage in terms of environmentally friendly use (Kim et al. 2012a, 2012b; Lee et al. 2011; Becknell and Hale 2011), such as recycled aggregates obtained from waste concrete (Kim et al. 2013; Kang et al. 2014).

Blast-furnace slag is composed of $\mathrm{SiO}_{2}, \mathrm{Al}_{2} \mathrm{O}_{3}, \mathrm{CaO}$, and $\mathrm{MgO}$, which is very similar to Portland cement, and so is the hydration reaction of blast-furnace slag. However, ground granulated blast-furnace slag has a so-called "latent hydraulic property" which cannot react without $\mathrm{CH}$ as a catalyst generated in the

*Contact Author: Kil-Hee Kim, Associate Professor,

Kongju National University,

275 Budae-daong, Cheonan, 330-717, Korea

Tel: +82-41-521-9335 Fax: +82-41-562-0310

E-mail:kimkh@kongju.ac.kr

(Received October 7, 2013 ; accepted July 1, 2014) hydration reaction of cement (Mehta and Monteiro 2006). Therefore, if cement is replaced with a large volume of ground granulated blast-furnace slag, the strength of the concrete decreases owing to the delay of the hydration reaction (Mehta and Monteiro 2006).

A lot of studies have reported that the long-term strength and durability of concrete with ground granulated blast-furnace slag is superior to that of concrete with Portland cement only. The higher the replacement ratio of the ground granulated blastfurnace slag is, the lower the required unit-water content for the same slump is. Therefore, ground granulated blast-furnace slag is good for making highflowing, high-strength, and high-durability concrete. If blast-furnace slag is used as an alternative cement material, the production cost of concrete can be reduced, as well as the $\mathrm{CO}_{2}$ emissions from Portland cement production.

Recently, the use of precast concrete structures, which can minimize fieldwork, ensure construction quality, and reduce construction time, is increasing. Because precast concrete members can be treated by steam curing in a factory during the early stage of concrete curing, it can improve the early-age strength of concrete and ensure its quality. Such advantages could resolve the problem of low early-age strength when a large amount of ground granulated blastfurnace slag is added to concrete so that, in terms of slag recycling, it is greatly beneficial. Despite the benefits of its use, few studies have been carried out on the use of ground granulated blast-furnace slag 
Table 1. Mix Design of Concrete

\begin{tabular}{|c|c|c|c|c|c|c|c|c|c|c|}
\hline \multirow{2}{*}{ Concrete } & \multirow{2}{*}{$\begin{array}{c}\text { Design } \\
\text { strength } \\
(\mathrm{MPa})\end{array}$} & \multirow{2}{*}{$\begin{array}{l}\text { W/B } \\
(\%)\end{array}$} & \multirow{2}{*}{$\begin{array}{l}\text { S/a } \\
(\%)\end{array}$} & \multicolumn{7}{|c|}{ Unit weight $\left(\mathrm{kg} / \mathrm{m}^{3}\right)$} \\
\hline & & & & Water & Cement & GGBS $^{*}$ & Sand & Gravel & $\mathrm{AE}$ & $\mathrm{AD}$ \\
\hline BG0 & \multirow{4}{*}{45} & 36.0 & 47.9 & 180 & 500 & 0 & 812 & 883 & 1.25 & 3.0 \\
\hline BG30 & & 34.4 & 47.9 & 172 & 350 & 150 & 817 & 888 & 1.75 & 3.0 \\
\hline BG50 & & 32.4 & 47.9 & 162 & 250 & 250 & 827 & 899 & 2.00 & 3.0 \\
\hline BG70 & & 30.4 & 47.9 & 152 & 150 & 350 & 836 & 909 & 2.50 & 3.0 \\
\hline
\end{tabular}

"GGBS: Ground Granulated Blast Furnace Slag

Table 2. Properties of Tested Specimens

\begin{tabular}{|c|c|c|c|c|c|c|c|c|}
\hline \multirow{2}{*}{ Specimens } & \multirow{2}{*}{$\begin{array}{l}f_{c}^{\prime} \\
(\mathrm{MPa})\end{array}$} & \multirow{2}{*}{$\begin{array}{l}\text { Replacement } \\
\text { ratio of GGBS }\end{array}$} & \multirow{2}{*}{$\begin{array}{c}b \\
(\mathrm{~mm})\end{array}$} & \multirow{2}{*}{$\begin{array}{c}d \\
(\mathrm{~mm})\end{array}$} & \multirow{2}{*}{$\begin{array}{c}a \\
(\mathrm{~mm})\end{array}$} & \multicolumn{3}{|c|}{ Reinforcement } \\
\hline & & & & & & Tension & Compression & Shear \\
\hline BG0 & 46.7 & $0 \%$ & \multirow{4}{*}{200} & \multirow{4}{*}{300} & \multirow{4}{*}{1200} & \multirow{4}{*}{$\begin{array}{r}3-\mathrm{D} 22 \\
f_{y}=448.7 \mathrm{MPa}, \\
E_{s}=160 \mathrm{GPa}\end{array}$} & \multirow{4}{*}{$\begin{array}{l}2-\mathrm{D} 13 \\
f_{y}=471.0 \mathrm{MPa} \\
E_{s}=163 \mathrm{GPa}\end{array}$} & \multirow{4}{*}{$\begin{array}{l}\mathrm{D} 10 @ 100 \\
f_{y}=496.6 \mathrm{MPa}, \\
E_{s}=154 \mathrm{GPa}\end{array}$} \\
\hline BG30 & 58.0 & $30 \%$ & & & & & & \\
\hline BG50 & 53.1 & $50 \%$ & & & & & & \\
\hline BG70 & 45.2 & $70 \%$ & & & & & & \\
\hline
\end{tabular}

in precast concrete. This study evaluated the flexural performance of precast concrete beams in order to promote the active use of ground granulated blastfurnace slag.

\section{Experimental Program \\ 2.1 Materials}

In this study, the design strength of concrete was designed to $45 \mathrm{MPa}$, as listed in Table 1. The compression test of the concrete cylinder was carried out at the time of the parent specimen test. The average compressive strengths of concrete are indicated in Table 2. and the compressive stress versus strain relationships of concrete are presented in Fig.1.(a).

Three types of reinforcement, D10 $\left(71.3 \mathrm{~mm}^{2}\right)$, D13 $\left(126.7 \mathrm{~mm}^{2}\right)$, and D22 $\left(387.1 \mathrm{~mm}^{2}\right)$, were used in this test. D13 for compression reinforcement had yield strength of $471.0 \mathrm{MPa}$ and D22 for tension reinforcement had yield strength of $448.7 \mathrm{MPa}$. The D10 steel bar with yield strength of $496.6 \mathrm{MPa}$ was used for shear reinforcement. The stress versus strain relationships of the reinforcement are shown in Fig.1.(b).

\subsection{Test Varieties}

A total of five specimens were cast and tested in this study to evaluate the flexural performance of precast concrete beams with ground granulated blast-furnace slag, as shown in Table 2. Each simply supported specimen was designed to have a clear span of 2,900 $\mathrm{mm}$ and a cross section of $200 \times 350 \mathrm{~mm}$, as seen in Fig.2. The shear span-to-depth ratio and the tension reinforcement ratio of the specimens were designed to 4 and $1.94 \%$, respectively, to induce flexural failure of the specimens. The shear reinforcement spaced at $100 \mathrm{~mm}$ was designed to prevent shear failure prior to flexural failure.

Strain gauges were attached to the tension, compression, and shear reinforcement to measure the deformation of the reinforcement, as seen in Fig.2.

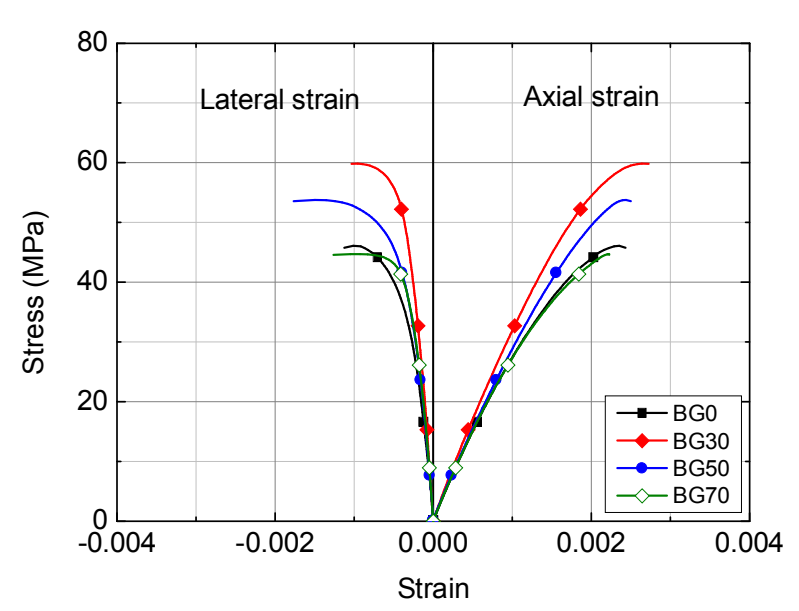

(a) Concrete

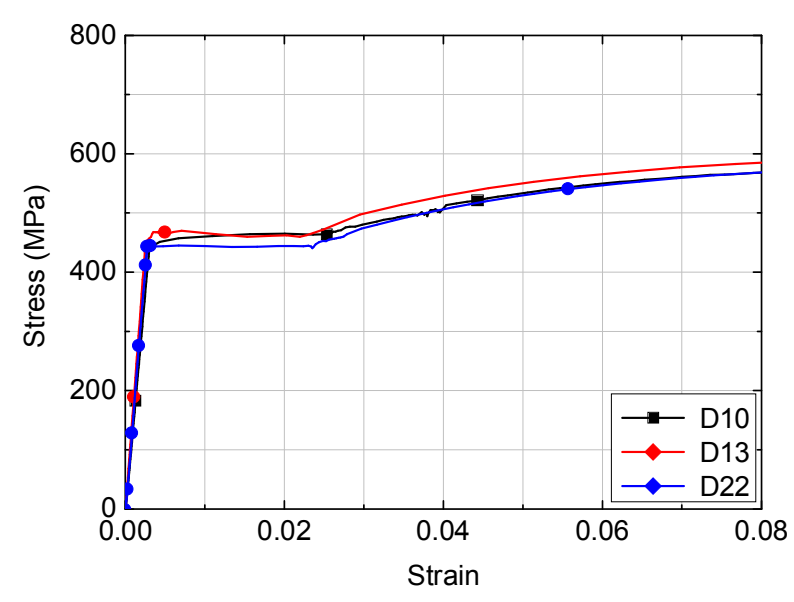

(b) Reinforcement

Fig.1. Stress versus Strain Curves of Materials

Furthermore, strain gauges were installed at the midspan of the specimen to track the neutral axis and curvature, as shown in Fig.2. 


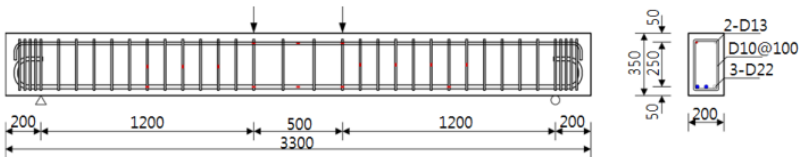

Fig.2. Details of Specimen

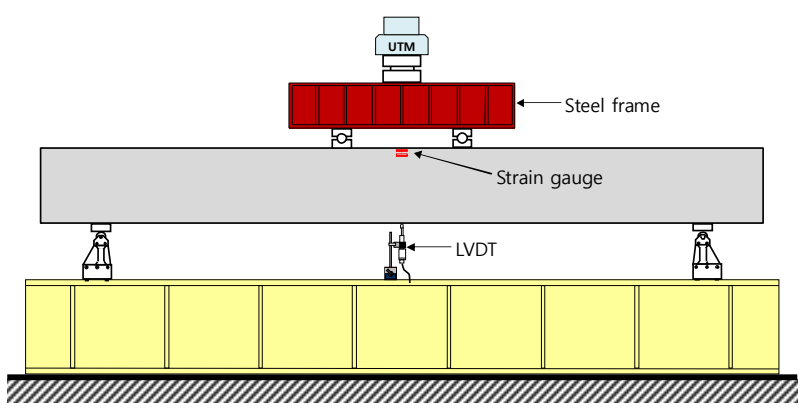

Fig.3. Test Setup of Specimen

\subsection{Test Setup}

As seen in Fig.3., a four-point loading system was applied to the specimens using a universal testing machine (UTM) with a load capacity of $1,000 \mathrm{kN}$. The applied load was removed when the post-peak load dropped to under approximately $85 \%$ of the maximum load. At the mid-span of the specimens, two linear variable differential transducers (LVDTs) were installed on the bottom of the specimens to measure the deflection of the specimens.

\section{Test Results}

\subsection{Load versus Deflection Relationships}

The load-deflection relationships measured from the experiment are shown in Fig.4. The deflection was the average value obtained from the LVDTs installed at the bottom of the specimens, as seen in Fig.3. It can be found from Fig.4. that all specimens exhibited similar ductile flexural behavior regardless of the replacement ratio of ground granulated blast-furnace slag.

The initial flexural crack occurred at $24.3 \sim 32.3 \mathrm{kN}$, whereas the tension reinforcement reached the yield strain at 222.1 241.5 kN. The maximum strength was found to be $273.2 \sim 280.9 \mathrm{kN}$, but the moment capacity declined due to the crushing of concrete in the compression zone, as seen in Fig.4.

\subsection{Crack Patterns}

The crack patterns of tested specimens according to the compressive strength of concrete and the replacement ratio of ground granulated blast-furnace slag are presented in Fig.5. The specimens had similar crack patterns even with varying values for the replacement ratio of the blast-furnace slag.

Flexural cracks formed at the mid-span of specimens during the initial loading, and expanded into both ends of the specimens as the load increased. After the tension reinforcement reached the yield strain, the cracks rapidly developed toward the loading points with an increase in crack width. Finally, the specimens failed in flexure with concrete crushing in

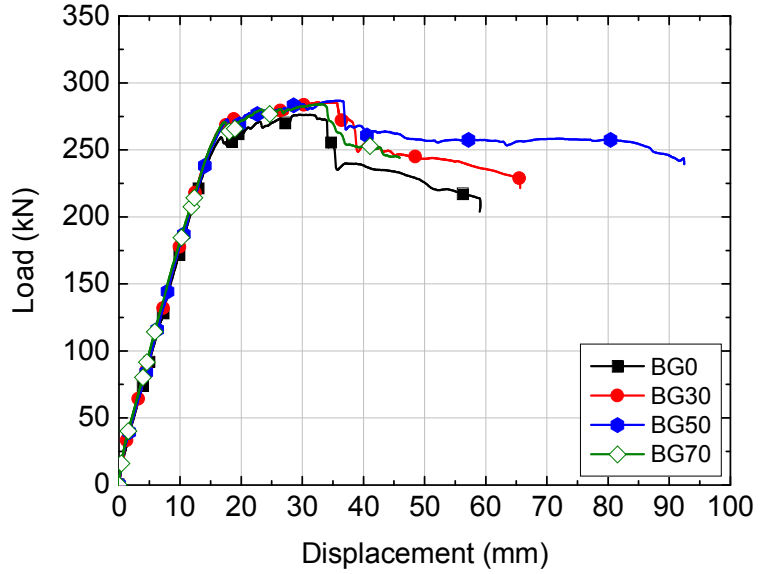

Fig.4. Load-Displacement Curve

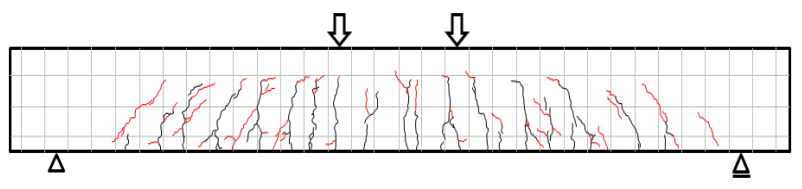

(a) BG0

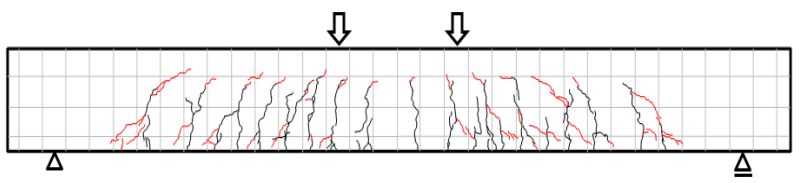

(b) BG30

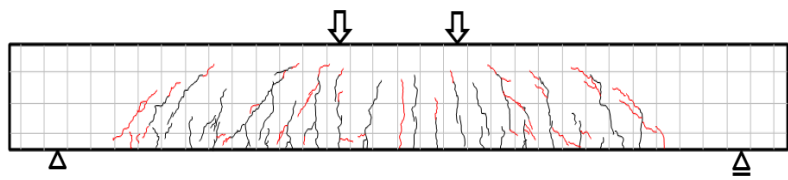

(c) BG50

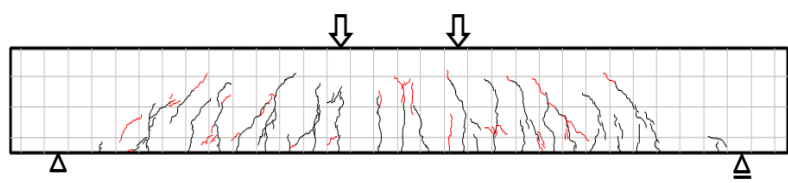

(d) BG70

Fig.5. Crack Patterns of Specimens after Failure

the compression zone between loading points.

\section{Discussion of Test Results}

\subsection{Flexural Strength}

The yield moment, $M_{y}$, can be obtined using equilbrium and Hook's law as follows:

$$
M_{y}=C_{c}\left(d-\frac{1}{3} k d\right)+C_{s}\left(d-d^{\prime}\right)=T\left(d-\frac{1}{3} k d\right)
$$

where $C_{c}$ is the concrete compression force, $C_{s}$ is the force in the compression reinforcement, $T$ is the tension force, $d$ is the effective depth, $d^{\prime}$ is the distance from extreme compression fiber to the centroid of compression tension reinforcement, and $k d$ is the distance from the neutral axis to the extreme compression fiber at yielding of tension reinforcement. 
Table 3. Experimental and Analytical Results of Tested Specimens

\begin{tabular}{|c|c|c|c|c|c|c|c|c|c|c|c|c|c|c|}
\hline \multirow{3}{*}{ Specimens } & \multirow{3}{*}{$\begin{array}{c}f_{c}^{\prime} \\
(\mathrm{MPa})\end{array}$} & \multirow{3}{*}{$\begin{array}{c}\text { GGBS } \\
(\%)\end{array}$} & \multicolumn{8}{|c|}{ Experimental results } & \multicolumn{4}{|c|}{ Experimental/Analytical } \\
\hline & & & \multicolumn{2}{|c|}{ Moment } & \multicolumn{3}{|c|}{ Curvature } & \multicolumn{3}{|c|}{ Deflection } & \multicolumn{2}{|c|}{ Moment } & \multicolumn{2}{|c|}{ Curvature } \\
\hline & & & $\begin{array}{c}M_{y} \\
(\mathrm{kN} \cdot \mathrm{m})\end{array}$ & $\begin{array}{c}M_{u} \\
(\mathrm{kN} \cdot \mathrm{m})\end{array}$ & $\begin{array}{c}\varphi_{y} \\
(\mathrm{rad} / \mathrm{mm})\end{array}$ & $\begin{array}{c}\varphi_{u} \\
(\mathrm{rad} / \mathrm{mm})\end{array}$ & $\frac{\varphi_{u}}{\varphi_{y}}$ & $\begin{array}{c}\Delta_{y} \\
(\mathrm{~mm})\end{array}$ & $\begin{array}{c}\Delta_{u} \\
(\mathrm{~mm})\end{array}$ & $\frac{\Delta_{u}}{\Delta_{y}}$ & $M_{y}$ & $M_{u}$ & $\varphi_{y}$ & $\varphi_{u}$ \\
\hline BG0 & 46.7 & 0 & 133.4 & 165.7 & 1.34 & 8.64 & 6.45 & 13.1 & 29.7 & 2.27 & 0.97 & 1.18 & 0.98 & 2.36 \\
\hline BG30 & 58.0 & 30 & 133.3 & 171.4 & 1.33 & 12.58 & 9.46 & 12.8 & 34.4 & 2.69 & 0.97 & 1.20 & 0.98 & 3.16 \\
\hline BG50 & 53.1 & 50 & 130.1 & 172.0 & 1.31 & 12.92 & 9.86 & 12.5 & 36.0 & 2.88 & 0.94 & 1.22 & 0.96 & 3.34 \\
\hline BG70 & 45.2 & 70 & 144.9 & 170.4 & 1.40 & - & - & 14.1 & 33.2 & 2.35 & 1.05 & 1.22 & 1.02 & - \\
\hline & & & & & & & & & & Mean & 0.98 & 1.21 & 0.99 & 2.95 \\
\hline
\end{tabular}

The ultimate moment, $M_{u}$, can be expressed using the equivalent stress block as follows:

$$
M_{u}=\alpha f_{c}^{\prime} \beta_{1} c b\left(d-\frac{\beta_{1} c}{2}\right)+A_{s}^{\prime} f_{s}^{\prime}\left(d-d^{\prime}\right)
$$

where $\alpha$ is the coefficient of the compression stress block, $f_{c}^{\prime}$ is the compressive strength of the concrete, $\beta_{1}$ is the ratio of the depth of rectangular stress block, taken as $a / c, a$ and $c$ is the distance from extreme compression fiber to neutral axis at first yield and ultimate, respectively, $b$ is the beam width, $A_{s}^{\prime}$ is the area of compression reinforcement, and $f_{s}^{\prime}$ is the stress of compression reinforcement. This study uses the coefficients of the compression stress block proposed by ACI 318-11 (ACI 2011).

Table 3. presents a comparison of the experimental and analytical results for yield moment calculated by using Eq. (1). As shown in Table 3., the analytical results for the yield moment accurately estimated the experimental results with a mean of 0.98 . It can be seen from Table 3. that the experimental results on ultimate moment, corresponding to maximum moment in this study, for each specimen exceed the analytical results proposed by ACI $318-11$ by about $20 \%$. This means that the ground granulated blast-furnace slag used in the precast concrete can harden with sufficient flexural strength even if up to $70 \%$ of ground granulated blastfurnace slag is replaced. However, further research is needed to find the allowable maximum replacement ratio of ground granulated blast-furnace slag in precast concrete.

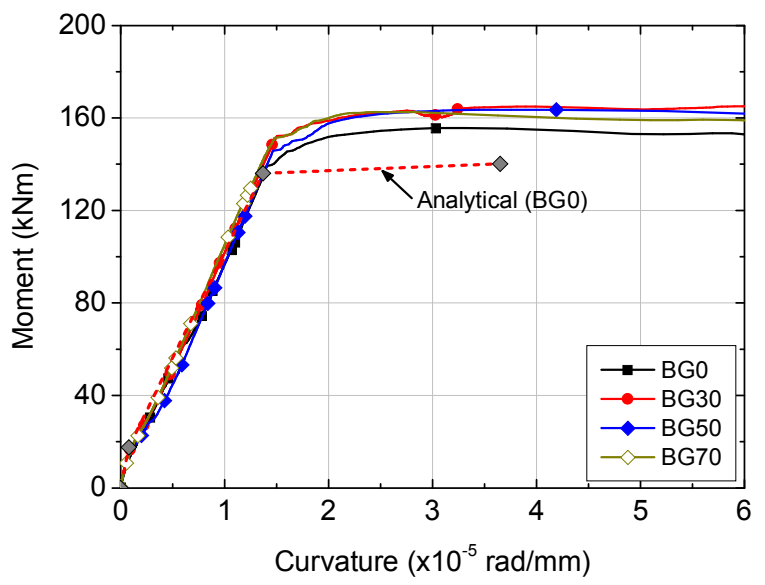

Fig.6. Moment-Curvature Relationships of Tested Specimens

\subsection{Moment versus Curvature Relationships}

Measured moment-curvature relations of each specimen are presented in Table 3. and Fig.6. The real curvature of each specimen was obtained by using the strain gauges attached to tension and compression reinforcement at the mid-span of specimens and the Bernoulli principle. In this study, ultimate means the state at reaching the flexural strength of the specimen.

The curvature at first yield of tension reinforcement can be calculated as follows:

$$
\varphi_{y}=\frac{f_{y} / E_{s}}{d(1-k)}=\frac{\varepsilon_{y}}{d(1-k)}
$$

where $f_{y}$ is the yield strength of tension reinforcement, $E_{s}$ is the elastic modulus of tension reinforcement, and $\varepsilon_{y}$ is the yield strain of tension reinforcement.

The ultimate curvature, $\varphi_{u}$, was calculated using the following equation:

$$
\varphi_{u}=\frac{\varepsilon_{c}}{c}=\frac{\varepsilon_{c} \beta_{1}}{a}
$$

where $\varepsilon_{c}$ is the strain of the concrete at extreme compression fiber.

Fig.6. indicates that analytical results for the moment-curvature relationship coincide fairly accurately with experimental results regardless of the replacement ratio of ground granulated blast-furnace slag. The experimental results of the yield curvature were obtained from the strain at the first yield of tensile reinforcement. As shown in Table 3., the experimental and calculated results for the yield curvature show good agreement with a mean of 0.99 .

The experimental results of the ultimate curvature were obtained from the curvature corresponding to ultimate moment in this study. As indicated in Table 3 , the specimen with ground granulated blast-furnace slag showed superior deformation performance that is approximately 3 times better than the analytical results. 4.3 Effective Moment of Inertia

ACI 318-11 (ACI 2011) recommends the following effective moment of inertia, $I_{e}$, proposed by Branson (1965) to calculate the deflection of RC members under service load.

$$
I_{e}=\left(\frac{M_{c r}}{M_{a}}\right) I_{g}+\left[1-\left(\frac{M_{c r}}{M_{a}}\right)^{3}\right] I_{c r}
$$




$$
M_{c r}=\frac{f_{r} I_{g}}{y_{t}}
$$

where $M_{c r}$ is the cracking moment, $f_{r}$ is the modulus of rupture, taken as $0.63 \sqrt{f_{c}^{\prime}}, I_{g}$ is the moment of inertia of the gross concrete section neglecting reinforcement, $y_{t}$ is the distance from the centroid axis of the cross section to the extreme fiber in tension, $M_{a}$ is the maximum moment in a member at the stage deflection is computed, and $I_{c r}$ is the moment of inertia of the cracked section transformed to the concrete.

When the bending moment, $M_{a}$, is applied to a simply supported beam under four-point loading, the theoretical deflection of the beam can be calculated as follows based on the theory of elasticity:

$$
\Delta_{s}=\frac{M_{a} a}{24 E_{c} I_{e}}\left(3 L^{2}-4 a^{2}\right)
$$

where $a$ is the shear span, $L$ is the clear span measured center to center of the supports, and $E_{c}$ is the elastic modulus of the concrete.

The moment of inertia of the specimen measured from the experiment at loading stage $M_{a}$ can be derived as follows:

$$
I_{\exp }=\frac{M_{a} a}{24 E_{c} \Delta_{\exp }}\left(3 L^{2}-4 a^{2}\right)
$$

where $\Delta_{\text {exp }}$ is the deflection measured by LVDTs installed under the mid-span of the specimen.

The analytical and experimental results of the effective moment of inertia of the specimens under service load are given in Fig.7. The analytical results of the effective moment of inertia calculated by using ACI 318-11 predicted well the experimental results, irrespective of the replacement ratio of the ground granulated blast-furnace slag. Therefore, the existing flexural theory can be used for predicting the flexural deformation of the precast concrete beams with ground granulated blast-furnace slag.

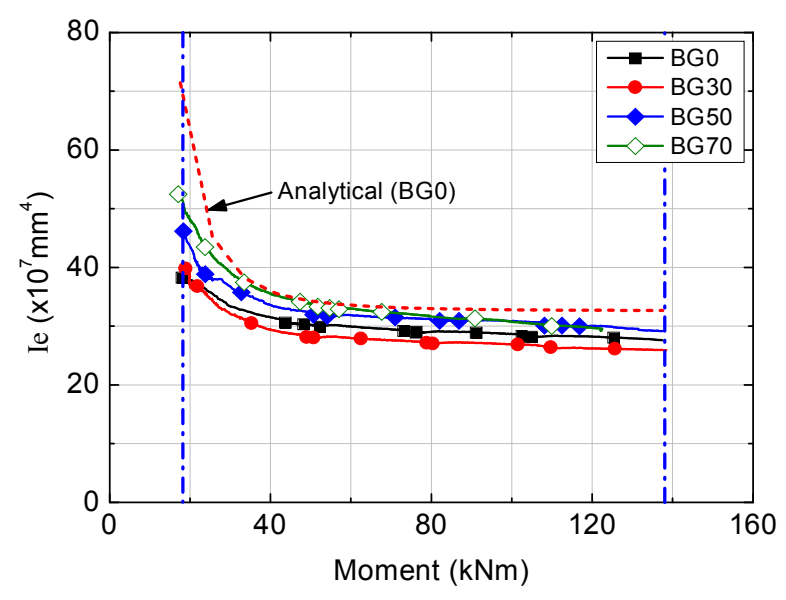

Fig.7. Effective Moment of Inertia of Specimens

\subsection{Ductility}

Ductility is the ability of a section, structural member, or structural system to maintain inelastic deformation prior to failure without substantial loss in resistance (Naaman et al. 1986). The ductility of structural members is usually represented as the ratio of the deformation at ultimate state to the deformation at first yield of tension reinforcement (Park and Paulay 1975). In this study, the ductility of specimens was evaluated using the following displacement ductility index.

$$
\mu_{\Delta}=\frac{\Delta_{u}}{\Delta_{y}}
$$

where $\Delta_{u}$ is the displacement corresponding to ultimate moment and $\Delta_{y}$ is the displacement at first yield of tension reinforcement.

The displacement ductility index of tested specimens is given in Table 3. As shown in Table 3., the ductility index of Specimen BG0 was 2.27, whereas those of Specimens BG30, BG50, and BG70 were 2.69, 2.88, and 2.35. That is, the ductility capacity of specimens with ground granulated blast-furnace slag is superior for use as structural members and is sufficiently safe.

\subsection{Serviceability}

The number of cracks and crack widths according to applied moment are shown in Fig.8. and Fig.9., respectively. For all specimens, the number of cracks and crack widths increased with greater load. In Fig.8., which shows the load-number of crack relationships for each specimen, all specimens exhibited similar loadcrack relationships except for Specimen BG70 with $70 \%$ replacement of ground granulated blast-furnace slag. Specimen BG70 had relatively fewer cracks in service load, but formed 23 cracks at ultimate load, similar to the number of cracks in other specimens.

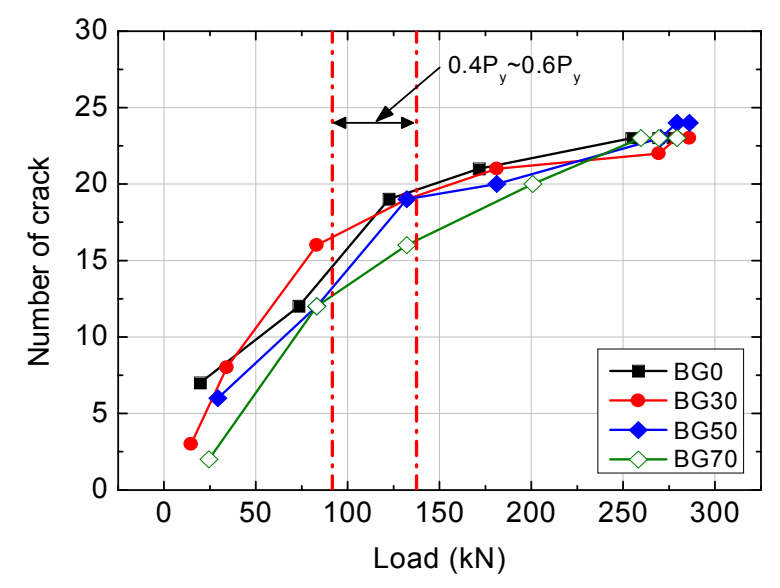

Fig.8. Number of Cracks Generated in Specimens

As shown in Fig.9., all specimens had a crack width smaller than $0.3 \mathrm{~mm}$ in the service load, thus satisfying the crack width limitation at service loads recommended by current code provisions (KCI 2012). 


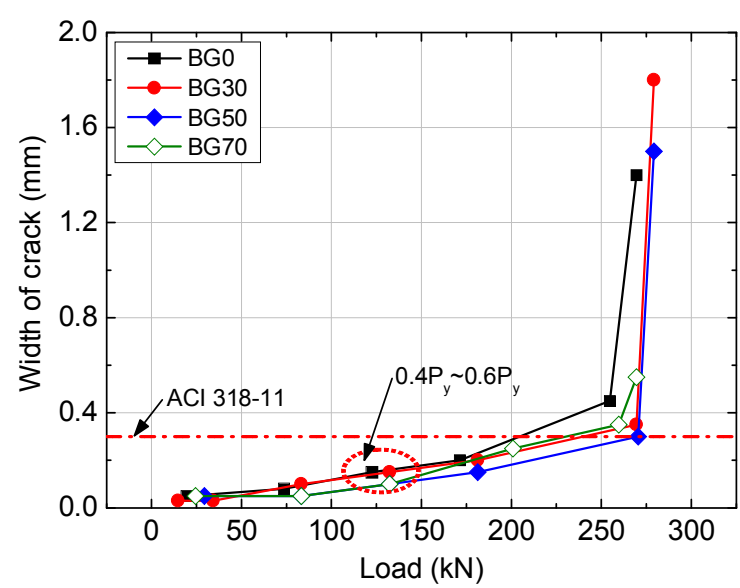

Fig.9. Width of Cracks Developed in Specimens

In addition, all specimens had similar crack widths in the service load state regardless of the replacement ratio of ground granulated blast-furnace slag.

\section{Conclusions}

This study evaluates the flexural performance of precast concrete beams with ground granulated blastfurnace slag. Based on the experimental results, the following conclusions were drawn:

1) In this experiment, precast concrete specimens with ground granulated blast-furnace slag showed similar flexural strength and higher ductility capacity compared to cement-only specimens.

2) The crack patterns and the change in effective moment of inertia for all specimens were similar, regardless of the replacement ratio of ground granulated blast-furnace slag.

3) Analytical results using existing flexural theory predicted well the yield and ultimate moment of specimens with ground granulated blast-furnace slag. In particular, the experimental results for ultimate moment of specimens with blast-furnace slag were approximately 1.2 times higher than existing analytical results.

4) This study evaluated the serviceability of precast concrete beams with ground granulated blastfurnace slag, and found that crack widths were smaller than $0.3 \mathrm{~mm}$ limited by current code provisions.

Based on the experimental results, precast concrete beam specimens with ground granulated blast-furnace slag showed superior flexural performance. However further research is needed to find the allowable maximum replacement ratio of ground granulated blast-furnace slag in precast concrete members.

\section{Notations}

$a=$ shear span

$A_{s}^{\prime}=$ area of compression reinforcement

$b=$ beam width

$C_{c}=$ concrete compression force

$C_{s}=$ force in compression reinforcement

$d=$ effective depth of beam

$d^{\prime}=$ distance from extreme compression fiber to the centroid of compression tension reinforcement

$E_{c}=$ elastic modulus of concrete

$E_{s}=$ elastic modulus of reinforcement

$f_{r}=$ modulus of rupture

$f_{y}=$ yield strength of reinforcement

$f_{c}^{\prime}=$ compressive strength of concrete

$f_{s}^{\prime}=$ stress of compression reinforcement

$I_{c r}=$ moment of inertia of cracked section transformed to the concrete

$I_{e}=$ effective moment of inertia

$I_{g}=$ moment of inertia of the gross concrete section neglecting reinforcement

$k d=$ distance from the neutral axis to the extreme compression fiber at yielding of tension reinforcing bars

$L=$ clear span measured center to center of the supports

$M_{a}=$ maximum moment in member at stage deflection

$M_{c r}=$ cracking moment

$M_{y}=$ yield moment

$M_{u}=$ ultimate moment

$T=$ tension force

$y_{t}=$ distance from the centroid axis of the cross section to the extreme fiber in tension

$\alpha=$ coefficient of the compression stress block

$\beta_{1}=$ ratio of the depth of rectangular stress block

$\varepsilon_{c}=$ strain of the concrete at extreme compression fiber

$\varepsilon_{y}=$ yield strain of tension reinforcement

$\varphi_{y}=$ curvature at first yield of tension reinforcement

$\varphi_{u}=$ ultimate curvature

$\Delta_{\text {exp }}=$ deflection measured LVDTs installed under the mid-span of the specimen

$\Delta_{y}=$ displacement at first yield of tension reinforcement

$\Delta_{u}=$ displacement corresponding to ultimate moment

\section{Acknowledgments}

This work was supported by Priority Research Center Program (2012-0006682) and Basic Science Research Program (2012R1A1A2039067) through the National Research Foundation of Korea (NRF) funded by the Ministry of Education, Science and Technology. This research was also financially supported by the Human Resources Development Program (No. 20114010203040) of the Korea Institute of Energy Technology Evaluation and Planning (KETEP) grant funded by the Korea government Ministry of Trade, Industry and Energy. 


\section{References}

1) ACI Committee 318. (2011) Building code requirements for structural concrete (ACI 318M-11) and commentary. American Concrete Institute, Farmington Hill, MI, p.503.

2) Becknell, N. P. and Hale, W. M. (2011) Effect of slag grade and cement source on the properties of concrete. International Journal of Concrete Structures and Materials, 5(2), pp.119-123.

3) Branson, D. E. (1965) Instantaneous and time-dependent deflections on simple and continuous reinforced concrete beams. HPR Report No. 7, Part 1, Alabama Highway Department, Bureau of Public Roads, pp.1-78.

4) Kang, T. H.-K., Kim, W., Kwak, Y.-K., and Hong, S.-G. (2014) Flexural testing of reinforced concrete beams with recycled concrete aggregates. ACI Structural Journal, 111(3), pp.607-616.

5) Kim, S.-W., Jeong, C.-Y., Lee, J.-S., and Kim, K.-H. (2013) Size effect in shear failure of reinforced concrete beams with recycled aggregate. Journal of Asian Architecture and Building Engineering, 12(2), pp.323-330.

6) Kim, S.-W., Lee, Y.-J., Kim, K.-H. (2012a) Flexural behavior of reinforced concrete beams with electric arc furnace slag aggregates. Journal of Asian Architecture and Building Engineering, 11(1), pp.133-138.

7) Kim, S.-W., Lee, Y.-J., and Kim, K.-H. (2012b) Bond behavior of $\mathrm{RC}$ beams with electric arc furnace oxidizing slag aggregates. Journal of Asian Architecture and Building Engineering, 11(2), pp.359-366.

8) Korea Concrete Institute. (2012) Korea structural concrete design code. Korea Concrete Institute, p.342 (in Korean).

9) Lee, K.-J., Yoo, S.-Y., Koo, J.-S., Cho, B.-S., and Lee, H.-H. (2011) Experimental study on the characteristics of rapid chilled converter slag by watering. International Journal of Concrete Structures and Materials, 5(2), pp.133-137.

10) Manso, J. M., Gonzalez, J. J., and Polanco, J. A. (2004) Electric arc furnace slag in concrete. Journal of Materials in Civil Engineering, ASCE, 16(6), pp.639-645.

11) Mehta, P. K., and Monteiro, P. J. M. (2006) Concrete: Microstructure, Properties, and Materials. $3^{\text {rd }}$ ed., McGraw-Hill, New York, p.659.

12) Naaman, A. E., Harajli, M. H., and Wight, J. K. (1986) Analysis of ductility in partially prestressed concrete flexural members. Prestressed Concrete Institute, 31(3), pp.64-87.

13) Park, R. and Paulay T. (1975) Reinforced concrete structures. Wiley, New York, p.769. 